\title{
EFFECT OF CHEMICAL INTERESTERIFICATION ON PHYSICAL AND CHEMICAL CHARACTERISTICS OF SUNFLOWER OIL AND TALLOW BLENDS \\ El-Shattory,Y.A. ${ }^{1}$;H.M.Salem ${ }^{2}$;Sherine M. Afifi ${ }^{1}$ and Saadia M. Aly ${ }^{1}$ \\ 1- Fats and Oils Department, National Research Center, Dokki, Cairo, Egypt. \\ 2- Biochemistry Department, Faculty of Agriculture, Cairo University, Cairo, Egypt.
}

\begin{abstract}
Sunflower oil and tallow were interesterified in different ratios (1:9, 2:8 and 4:6 $\mathrm{w} / \mathrm{w})$, at various degrees of temperature, for many periods of time. Using sodium methoxide $(0.3 \% \mathrm{w} / \mathrm{w})$ and sodium hydroxide: glycerol: water $(1: 2: 3 \mathrm{w} / \mathrm{w})$ as catalysts. Acid value, iodine value, peroxide value and melting point of interesterified and noninteresterified (control) blends were analysed. Solid fat content, trans fatty acids and fatty acid compositions of selected interesterified blends were determined. lodine values of all blends with all conditions were more or less equal to iodine values of their control samples, while acid values of interesterified samples were decreased relative that of control sample. Interesterified samples which obtained using sodium hydroxide: glycerol: water $(1: 2: 3 \mathrm{w} / \mathrm{w})$ gave preferable peroxide value more than that using sodium methoxide $(0.3 \% \mathrm{w} / \mathrm{w})$. Trans fatty acids of selected interesterified samples using sodium hydroxide: glycerol: water (1:2:3 w/w) were better than those selected interesterified samples using sodium methoxide $(0.3 \% \mathrm{w} / \mathrm{w})$.

Keywords: Chemical interesterification, blend, sunflower oil, tallow, sodium methoxide, sodium hydroxide: glycerol: water, fatty acid compositions, solid fat content, melting point, trans fatty acids.
\end{abstract}

\section{INTRODUCTION}

Most vegetable oils in their native state have only limited applications due to their specific chemical compositions. To widen their use, vegetable oils are modified, either chemically by hydrogenation or interesterification, or physically by fractionation(Petrauskaite et al.,1998). Interesterification is one of the most important process for modifying the physicochemical characteristics of oils and fats (Noor Lida et al.,2002). During interesterification, fatty acids (FAs) are exchanged within (interesterification) and among (interesterification) triacylglycerols (TAGs) until a thermodynamic equilibrium is reached (Rodríguez et al., 2001). Interesterification of solid fats and vegetables oils can produce a fat blend with optimum characteristics.

Rearrangement or randomization of acyl residues in triacylglycerols has provided fats or oils with new physical properties (Zeitoun et al., 1993). In most oils and fats, unsaturated fatty acids preferentially occupy the 2postions of the triacylglycerol molecules. Fatty acids are distributed in a random manner among the triacylglycerol molecules by chemical interesterification. The degree of unsaturation or isomeric state of the fatty acid does not change (Noor Lida et al.,2002). 
However, during partial hydrogenation, some cis double bonds are isomerised into their trans former. In the past few years, several nutritional studied have suggested a direct relationship between trans fatty acids and increased risk for coronary heart diseases (Karabulut et al., 2004).

Chemical interesterification has long been used to modify oils and fats into functional products. It modifies the physical properties of oils by rearranging the distribution of fatty acids on the glycerol backbone without changing their chemical composition. With the rising concerns over the nutritional impact of trans fatty acids on health, interesterification has become more popular for the preparation of low or zero trans functional plastic fats (Norizzah et al., 2004)

In interesteritication, fatty acids are exchanged within (interesterification) and among (interesterification) triacylglycerols until a thermodynamic equilibrium is reached [Rousseau et al.(1996), and Konishi et al. (1993)]. The objective of this study was to manufacture shortening by chemical interesterification (IT) of tallow-sunflower oil mixtures and to evaluate the physical, thermal, chemical, and textural properties for the purpose of finding a replacement for hydrogenated fish oil (Rodríguez et al., 2001).

The aim of this work is to assist in the proper choice of oils, catalyst and conditions including temperature and time to produce a large variety of plastic lipid blends of various melting point ranges which can be used in many segments of the food industry with zero trans hard phase having good physical and chemical characteristics to use it in manufacturing margarine, vanaspati and shortenings.

\section{MATERIALS AND METHODS}

Materials :

1-a- Refined, bleached and deodorized sunflower oil was obtained from local supermarket.

2-b- Tallow was obtained from a local butcher.

3-c- Sodium methoxide was purchased from Electro Sciente Company 4-dSodium hydroxide and glycerol were purchased from El-Nasr

Pharmaceutical Chemicals Company.

5-e- Sunflower oil: tallow blends were prepared with ratios (1:9, 2:8 and 4:6 $w / w)$.

All used chemicals and solvents were of highly pure grade.

\section{Methods:}

- Interesterification Process:

Portions $(100 \mathrm{~g})$ of each blend was heated under the selected temperatures $\left(60,80\right.$ and $\left.135^{\circ} \mathrm{C}\right)$ using periods of time $(0.5,1$, and $1.5 \mathrm{~h})$. When the blend had reached the reaction temperature, the catalyst $[0.3 \%$ of sodium methoxide or $0.6 \mathrm{ml}$. of sodium hydroxide: glycerol : water (1:2:3 $\mathrm{w} / \mathrm{w})]$ was added while the blend was vigorously stirred. To end the reaction, an excess of citric acid was added to neutralize the catalyst. The excess of citric acid and sodium methoxide was removed with warm water washes 
three times. Residual water was removed with an excess of anhydrous sodium sulfate, followed by decantation.

Finally, the interesterified blends were analyzed for determination of chemical analysis (lodine value, Acid value, Peroxide value, Fatty acid compositions, Trans fatty acids ) and physical analysis (Melting point, Solid fat content).

- Determination of iodine value (IV), acid value (AV) and peroxide value (PV) were carried out according to AOCS Official Methods (1996).

\section{-Determination of fatty acid composition: \\ Preparation of fatty acid methyl esters:}

About $0.2 \mathrm{gm}$ of the non-interesterified and some selected interesterified samples were mixed with $30 \mathrm{ml}$ sulfuric acid : methanol $(4: 96$ $\mathrm{v} / \mathrm{v}$ ) in a $250 \mathrm{ml}$ round bottom flask. The contents were then heated under reflux for about three hours. The methyl esters were thrice extracted with petroleum ether $\left(40-60^{\circ} \mathrm{C}\right)$ then it was washed several times with distilled water till the washings were neutral to phenol phthalein. The combined fatty acids methyl esters layers were dried over anhydrous sodium sulfate and filtered. The petroleum ether was then removed using a rotary evaporator and an aliquots of the fatty acid methyl esters were analyzed by gas chromatography (Farag 1994).

\section{- Gas liquid chromatographic analysis of fatty acids methyl esters:}

The identification of the components of fatty acids methyl esters was done using gas liquid chromatography on a Hewlett Packard Model 6890 chromatograph equipped under the following conditions:

- Separation was done on an INNO wax (polyethylene glycol) Model No. $19095 \mathrm{~N}-123,240^{\circ} \mathrm{C}$ maximum, capillary column $30.0 \mathrm{~m} \times 530 \mu \mathrm{m} \times 1.0$ $\mu \mathrm{m}$, nominal flow $15 \mathrm{ml} / \mathrm{min}$. with average velocity $89 \mathrm{~cm} / \mathrm{sec}$. and pressure 8.2 psi.

-Column temperature was $240^{\circ} \mathrm{C}$ with temperature programming : Initial temperature $100{ }^{\circ} \mathrm{C}$ to $240^{\circ} \mathrm{C}$ maximum with $10^{\circ} \mathrm{C}$ rising for each minute and then hold at $240^{\circ} \mathrm{C}$ for ten minutes.

- Injection temperature $280^{\circ} \mathrm{C}$, back inlet, with split ratio $8: 1$, split flow $120 \mathrm{ml} /$ min., gas saver $20 \mathrm{ml} / \mathrm{min}$.

- Carrier gas was nitrogen with flow rate $15 \mathrm{ml} / \mathrm{min}$.

- Flame ionization detector temperature $280^{\circ} \mathrm{C}$.

- Hydrogen flow rate $30 \mathrm{ml} / \mathrm{min}$.

- Air flow rate $300 \mathrm{ml} / \mathrm{min}$.

- Determination of Melting Point

Melting point was determined to non and interesterified blends by electeric melting point apparatus ( Electrothermal 9100) according to AOCS Official Method (1996).

-Determination of Solid Fat Content

SFC was measured using pulse NMR (Nuclear Magnetic Resonance), apparatus model Moran SFC. Company Oxford (England). SFC was measured in temperature range $10^{\circ} \mathrm{C}-40^{\circ} \mathrm{C}$, calibration and verification by standard tubes $(0,29.65,70.3) \%$ according to AOCS Official Method (1996). 
- Determination of Trans Fatty Acids:

Analysis using Fourier Transform Infra Red (FTIR) instrument:

Non-interesterified and some selected interesterified samples were subjected to FTIR analysis on a Nexus 670 Fourier Transform Infra Red spectrometer, Thermo Nicolet, USA. The FTIR spectra were analyzed using

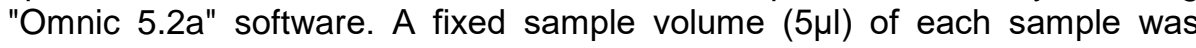
carefully and homogeneously spread between two $\mathrm{KBr}$ disks of fixed weights. The samples were referenced to their own blank $\mathrm{KBr}$ disks. For collection of the data, a DTGS detector and $\mathrm{KBr}$ beam - splitter were used. The measuring at wave length $850-1150 \mu$. According to AOCS Official Methods (1996).

\section{RESULTS AND DISCUSSIONS}

The determined properties of interesterified sunflower oil : tallow blends of three different ratios $1: 9 ; 2: 8 ; 4: 6 \mathrm{w} / \mathrm{w}$, at temperatures $60^{\circ}, 80^{\circ}$ and $135^{\circ} \mathrm{C}$ for different times $(0.5 \mathrm{hr}$, hour and $1.5 \mathrm{hr})$ using sodium methoxide $(0.3 \% \mathrm{w} / \mathrm{w})$ and sodium hydroxide : glycerol : water $(1: 2: 3 \mathrm{w} / \mathrm{w})$ catalysts, were acid value, iodine value, peroxide value and melting point value. All result were comparable to that of fresh sunflower-tallow blend (control).

\section{A-1- Acid value of the interesterified sunflower oil - tallow blends}

Acid values of interesterified sunflower oil - tallow blends samples are illustrated in figures (1-6). Concerning of acid value of the interesterified samples at different temperatures using both catalysts decreased from control sample and the maximum decrease got by using sodium hydroxide: glycerol : water $(1: 2: 3 \mathrm{w} / \mathrm{w})$ catalyst for interesterified blend of sunflower oil tallow blend with $4: 6$ ratio at $60^{\circ} \mathrm{C}$ for $1.5 \mathrm{hr}$ and at $135^{\circ} \mathrm{C}$ for $1 \mathrm{hr}$.

A-2- lodine value of the interesterified sunflower oil - tallow blends

These iodine values are shown in figures (7-12). Regarding these values the interesterified samples using both catalysts for different times and at different degrees of temperature of all blends ratios were more or less equal to iodine values of their control samples.

\section{A-3- Peroxide value of the interesterified sunflower oil - tallow blends}

Peroxide value of all interesterified samples, are drawn in figures (1318). It is clear that interesterified samples obtained using sodium hydroxide: glycerol : water (1:2:3 w/w) catalyst gave preferable peroxide value more than that of using sodium methoxide $(0.3 \% \mathrm{w} / \mathrm{w})$ especially of the interesterified samples of all ratios at $60^{\circ} \mathrm{C}$ and at $135^{\circ} \mathrm{C}$ for all time periods.

A-4- Melting point of the interesterified sunflower oil - tallow blends

The melting point of the interesterified samples of sunflower oil : tallow blend are reported in figures (19-24). We can notice that using sodium methoxide catalyst during interesterification at $60^{\circ} \mathrm{C}$, the melting point of the interesterified sunflower oil - tallow blend with ratio (2:8) for one hour was less than that of the other samples. While at $80^{\circ} \mathrm{C}$ the least melting point for the same ratio was happened in $0.5 \mathrm{hr}$ interesterification and at $135^{\circ} \mathrm{C}$ the lowest melting point was got with the interesterified sunflower oil : tallow ratio $(4: 6 \mathrm{w} / \mathrm{w})$ for 1 hour. 
Concerning sodium hydroxide : glycerol : water $(1: 2: 3 \mathrm{w} / \mathrm{w})$ catalyst the melting point of the interesterified sunflower oil : tallow blend samples at different temperatures for different ratios in different time periods were more or less the same.

\section{A-5- Solid fat content of selected interesterified sunflower oil - tallow} blends

Solid fat indices of the control and interesterified sunflower oil : tallow blend samples $(1: 9 \mathrm{w} / \mathrm{w})$ ratio using sodium methoxide $(0.3 \% \mathrm{w} / \mathrm{w})$ catalyst at $80^{\circ} \mathrm{C}$ and $135^{\circ} \mathrm{C}$ shown in figures $(25-26)$ and these using sodium hydroxide: glycerol : water $(1: 2: 3 \mathrm{w} / \mathrm{w})$ catalyst at $60^{\circ} \mathrm{C}$ and $135^{\circ} \mathrm{C}$ recorded in figures (27-28). It is clear that the preferable sample was the interesterified sunflower oil : tallow at $60^{\circ} \mathrm{C}$ using sodium hydroxide: glycerol : water catalyst for one hour.

\section{A-6- Trans fatty acids of selected interesterified sunflower oil - tallow} blends

It is clear from figures (29-30) that trans fatty acid of four selected interesterified sunflower oil: tallow blend $(1: 9 \mathrm{w} / \mathrm{w})$ ratio at $60^{\circ} \mathrm{C}$ using sodium hydroxide: glycerol : water $(1: 2: 3 \mathrm{w} / \mathrm{w})$ catalyst for one hour and that at $135^{\circ} \mathrm{C}$ using the above catalyst for half hour gave the preferable trans fatty acids in interesterified blend those that of interesterified blend using sodium methoxide $(0.3 \% \mathrm{w} / \mathrm{w})$.

\section{A-7- Fatty acid compositions of selected interesterified sunflower oil - tallow blends}

These values are represented in figures (31-34). Interesterification of sunflower oil: tallow $(1: 9 \mathrm{w} / \mathrm{w})$ blend using sodium methoxide $(0.3 \% \mathrm{w} / \mathrm{w})$ catalyst caused reduction of unsaturated fatty acid and increasing of saturated fatty acid percentages. While interesterified using sodium hydroxide: glycerol : water $(1: 2: 3 \mathrm{w} / \mathrm{w})$ catalyst increased unsaturated fatty acid and decreased saturated fatty acid percentages. Interesterified sunflower oil: tallow $(1: 9 \mathrm{w} / \mathrm{w})$ blend at $60^{\circ} \mathrm{C}$ and $135^{\circ} \mathrm{C}$ using sodium hydroxide: glycerol : water (1:2:3 w/w) for one hour and half hour gave blends have unsaturated fatty acids about $40 \%$ of total fatty acids.

The changes in triacylglycerol profiles were reflected in the solid fat content profiles of the blends (Noor Lida et al., 2007)

Forssell et al. (1993), the melting point reduction achieved by interesterification was depend on the mass fractions of the substrate the lower the mass fraction of tallow, the larger the reduction of the melting point.

It has been found that after interesterification the concentrations of free fatty acids and partial acylglycerols increased. On the other hand the slip melting temperatures and solid fat contents in triacylglycerols isolated from interesterified fats and their oxidative stability were lower if compared with non-interesterified, initial blend (Kowalski et al., 2004). 
El-Shattory, Y.A. et al.

$1-6$ 
J. Agric. Sci. Mansoura Univ., 33 (5), May, 2008

7-12

3929 
El-Shattory, Y.A. et al.

13-18

3930 
J. Agric. Sci. Mansoura Univ., 33 (5), May, 2008

$19-24$

3931 
El-Shattory, Y.A. et al.

25-28 
J. Agric. Sci. Mansoura Univ., 33 (5), May, 2008

$29-30$

3933 
El-Shattory, Y.A. et al.

31-34

3934 
The interesterification increased both free fatty acids and polar fraction contents and the increases were higher in chemical interesterified fat mixtures (Brys et al., 2004).

The acidity and content of polar fractions were increased after interesterification. (Kowalska et al., 2005). work.

These finding more or less agree with the results got in this piece of

\section{REFERENCES}

AOCS (1996). Official Methods and Recommended Practices of the American Oil Chemists' Society, AOCS, Champaign, IL

Brys, J.; Gruczynska, E.; Kowalski, B. and Tarnowska, K. (2004) "Interesterification of milk fat and rapeseed oil mixtures". Zywnosc, 11 (3, Sppl.), 18-26 .

Farag,R.S. (1994) "Influence of microwave and conventional heating on the quality of lipids in model and food system" Fat Sci. Technol.96 (6):215222.

Forssell, P.; Parovuori, P.; Linko, P. and Poutanen, K. (1993). "Enzymatic transesterification of rape seed oil and lauric acid". J. Am. Oil Chem. Soc. 70(11): 1105- 1109.

Karabulut, I.; Turan, S. and Ergin, G. (2004) "Effect of chemical interesterification on solid fat content and slip melting point of fat/oil blends". Eur. Food Res. Technol. 218: 224-229

Konishi, H.; Neff, W. and Mounts, T. (1993) "Chemical interesterification with regioselesctivity of edible oils". J. Am. Oil Chem. Soc. 70:411-415

Kowalska, M.; Brys, J.; Zbikowska, A. and Kowalski, B. (2005) "Interesterification blends made of beef tallow fractions and rapeseed oil". Zywnosc , 12 (2, Supl.), 97-113.

Kowalski, B.; Tarnowska, K.; Gruczynska, E. and Bekas, w. (2004) "Chemical and enzymatic interesterification of beef tallow and rapeseed oil blend with low content of tallow". Journal of Oleo science, 53 (10), 479-488.

Noor Lida, H.M.D.; Sundram, K.; Siew, W.L.; Aminah A. and Mamot, S.(2002). "TAG composition and solid fat content of palm oil, sunflower oil, and palm kernel olein blends before and after chemical interesterification". J. Am. Oil Chem. Soc. 79:1138-1143

Noor Lida, H.M.D; Kalyana, S. and Nor Aini, I. (2007) "Effect of chemical interesterification on triacyiglycerol and solid fat contents of palm stearin, sunflower oil and palm kernel olein blends". European Journal of Lipid Science and Technology, 109(2), 147-156.

Norizzah, A.R.; Chong, C.L.; Cheow, C.S. and Zaliha, O. (2004) "Effect of Chemical interesterification on physicochemical properties of palm stearin and palm kernel olein blends". Food Chemistry 86:229-235 


\section{El-Shattory, Y.A. et al.}

Petrauskaite, V.; De Greyt, W.; Kellens, M. and Huyghebaert A (1998). "Physical and chemical properties of trans -free fats produced by chemical interesterification of vegetable oil blends". J. Am. Oil Chem. Soc. 75:489-493

Rodríguez, A.; Castro, E.; Salinas, M. C.; López, R. and Miranda, M. (2001) "Interesterification of Tallow and Sunflower oil ". J. Am. Oil Chem. Soc. 78 (4):431—436

Rousseau D, K.; Forestière, A. Hill and Marangoni, A. (1996) "Restructuring butterfat through blending and chemical interesteri - fication.1.Melting behavior and triacylglycerol modifications" J. Am. Oil Chem. Soc. 73:963-971

Zeitoun, M.A.M.; Neff, W.E.; List, G.R. and Mounts, T.L. (1993) "Physical properties of interesterified fat blends". J. Am. Oil Chem. Soc. 70 (5):467 -471.

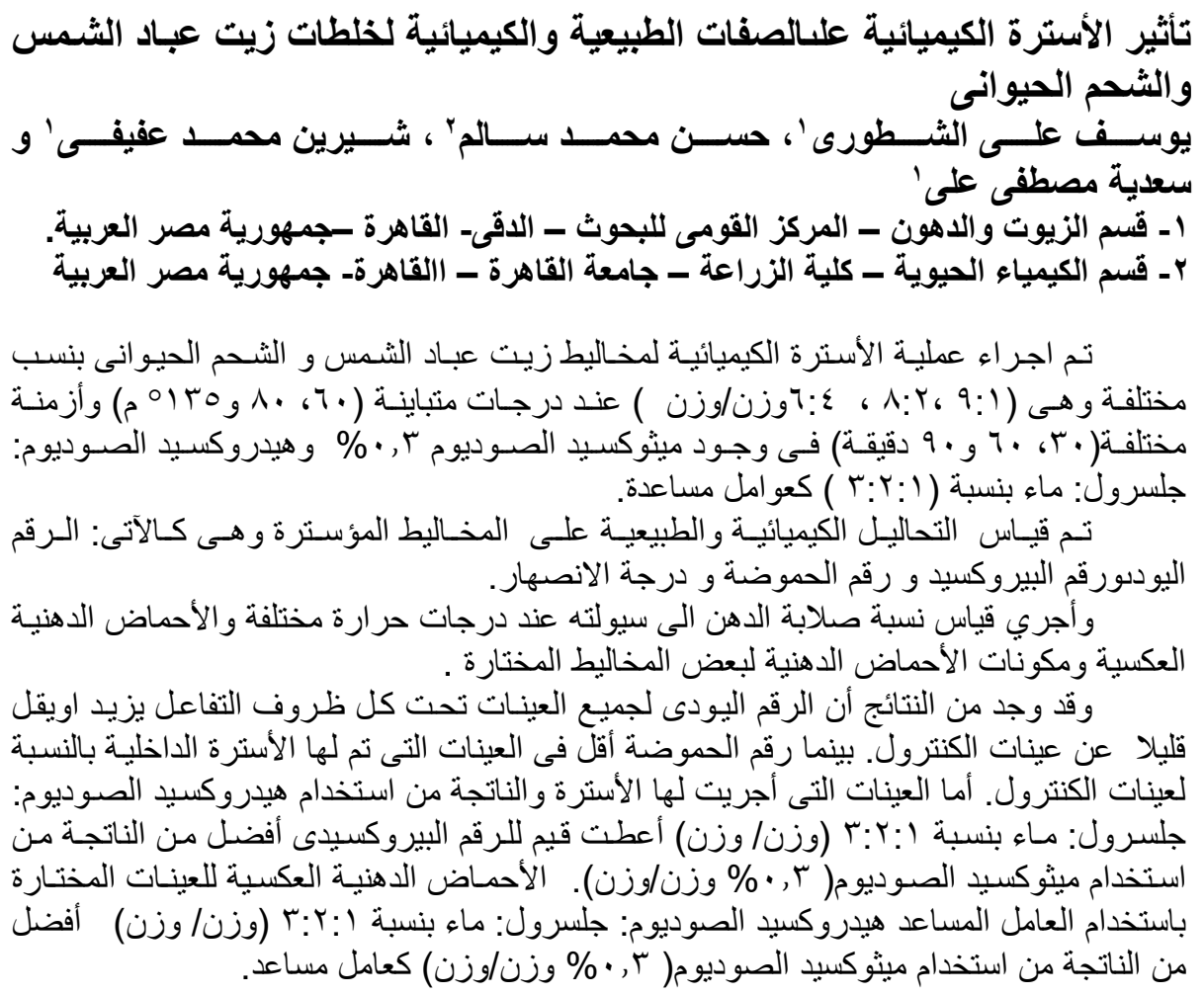

